\title{
Evaluation of siliciclastic and carbonatic reservoirs in Campos Basin using cross-plots
}

\author{
Rodrigo da Silva ${ }^{1}$, Abel Carrasquilla ${ }^{1}$ \& Mohammed Saad Allahham ${ }^{1}$
}

\begin{abstract}
${ }^{1}$ Petroleum Engineering and Exploration Laboratory, Darcy Ribeiro
Highway, Brennand Avenue S/N, Imboassica, Macae-RJ, 27930-480.
Copyright 2019, SBGf - Sociedade Brasileira de Geofísica

This paper was prepared for presentation during the $16^{\text {th }}$ International Congress of the Brazilian Geophysical Society held in Rio de Janeiro, Brazil, 19-22 August 2019.

Contents of this paper were reviewed by the Technical Committee of the $16^{\text {th }}$ International Congress of the Brazilian Geophysical Society and do not necessarily represent any position of the SBGf, its officers or members. Electronic reproduction or storage of any part of this paper for commercial purposes without the written consent of the Brazilian Geophysical Society is prohibited.
\end{abstract}

\section{Abstract}

The characterization of an oil reservoir is an important task from the discovery of the resources to its management. When properly applied, current well exploration and interpretation techniques can provide substantial reductions in the costs of evaluating, developing and operating oil reservoirs. The approach integrates geology, geophysics, reservoir engineering, petrophysics, economy and data mining and, specifically, petrophysics deals with the fundamental chemical and physical properties of the porous media and fluids in the reservoir rocks. These properties and their relationships are used to recognize and evaluate geological formations, capping rocks, reservoirs and aquifers. Within petrophysics, well logs are one of the most useful of the various types of methods used in the reservoir characterization. The log interpretation uses porosity, density, resistivity, delay time and natural gamma radiation parameters to construct cross - plots, which characterized carbonate and siliciclastic reservoirs from Namorado and B oilfields of Campos Basin, respectively. Thus, logs and laboratory porosities were used to construct Hingle, Pickett, Buckles, Neutron - Density and MN cross - plots. From these graphics, the reservoirs were characterized, and the results were comparable to those of Petrobras and the literature.

\section{Introduction}

Cross plots are common tools in data interpretation and, for this reason, Macini \& Mesini (2002) used them to characterize oil reservoirs. In accord with Buryakovsky et al. (2012), the combination of the information from multiple logs can provide important information to understand subsurface formations. The simplest means of combining multiple logs is a multitrack display or a cross plot, which allow the analyst to see the data more effectively than looking at each log individually, being is another method for visualizing petrophysical data (Tiab \& Donaldson, 2015; Tittman,1986). Aguilera (2004) indicated that lithology and fluid variations can be identified by these graphics. Nevertheless, Asquith \& Krygowski (2004) utilized them to discriminate mineralogy, estimate porosity and reveal argilosity. In this way, we utilized cross plots to delineate lithofacies and predict the quality of siliciclastic and carbonatic reservoirs in Campos Basin.

In relation to the geological context, the Campos Basin is one of the various sedimentary basins mapped along the Brazilian margin. The basin originated during the breakup of the Gondwana supercontinent (Guardado et al., 1989, 2000). In the tectonic adjustment of the plates, the mesozoic disruption culminates in the division of the very large and reasonably rigid continental blocks (Chang et al., 1992). During the Albian - Cenomanian, marine conditions predominated in the basin. Thus, the Macae Formation consists of clastic and oolitic carbonates (Quissamã Member) that, locally, appear completely dolomitized, which are Albian carbonate reservoirs of the lower part of group (Carvalho, et al., 1995). The vertical succession of Outeiro Member includes calcilutite, marl and shale (Formoso, 1991). The turbiditic sandstone of Namorado Member, on the other hand, in the more proximal portions, the Macae Formation consists of poorly selected conglomerate and sandstone of the Goitacas Member, which are turbidite reservoirs of Albian superior to the Middle/Upper Cenomian of the Upper Macae Group (Milani et al., 2000).

\section{Methodology}

The data that were used in this work belong to Namorado and $B$ oilfields. The gamma ray $(G R)$, neutron porosity (NPHI), sonic (DT), density $(\mathrm{RHOB})$ and resistivity $(\mathrm{RT})$ basic logs of these two oilfields were used and compared with the porosity measured in laboratory (Kirby et al.,1960). In order to construct the graphs and to visualize the logs, the software Interactive Petrophysics (IP) (LR Senergy, 2018) was used. Initially, the basic logs were 
used to identify the zones of interest, and, posteriorly, the Hingle (1959), Pickett (1973), Buckles (1965), NeutronDensity (Burke et al., 1959) and M-N (Poupon et al., 1971) cross-plots were used to obtain the petrophysical characteristics of both oilfields. From Table 1 it can be seen, respectively, the properties that can be derived from the above-mentioned cross-plots (Clavier et al., 1976).

\section{Results}

\section{Namorado Oilfield}

Two areas of interest are identified when the basic logs of Well NA02 of Namorado Oilfield are analyzed (Figure 1). Featured in black, the first zone, ranging from depth of 3038 to $3057 \mathrm{~m}$, and the second one in red, which goes from the depth of 3092 to $3096 \mathrm{~m}$. The regions of interest

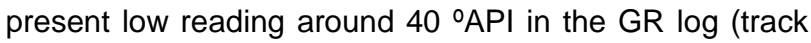
2), which means a cleaner sandstone (little clay). The DT log reduces from 90 to $70 \mu \mathrm{s} / \mathrm{ft}$, which indicates growing in the cementation (track 3). The RT log increases substantially from 1 to 2000 ohm.m, showing the presence of hydrocarbons (track 4). In RHOB-NPHI track, the first zone of interest shows a decline in the NPHI log from 26 to 16 and an increase in the log of the RHOB from 2.05 to 2.20. A crossroad occurs between these logs, which indicates the presence of hydrocarbons (track $5)$.

The Hingle cross plots RT-RHOB and RT-DT were made to evaluate density ( $\left.\rho_{\mathrm{MA}}\right)$ and delay time (DT $\mathrm{MA}_{\mathrm{MA}}$ ), where $M A$ is the rock matrix. Figures 2 ( $a$ and $b$ ) shows $\rho M A=2.689 \mathrm{gr} / \mathrm{cm}^{3}$ and $D T_{M A}=53.8 \mu \mathrm{s} / \mathrm{ft}$, which are very close to 2.67 and 53.52 found by Ribeiro \& Stevanato (2011). The porosity was calculated using the equations $\left.\phi_{R H O B}=(\rho M A-\rho B) /(\rho M A-\rho F)\right)$ and $\phi_{D T}=\left(\left(D T-D T_{M A}\right) /\left(D_{F}-D T_{M A}\right)\right)$ (Schön, 2015). In them, $\rho$ MA is the density of the matrix, $\rho B$ is the log of density, $\rho F$ is the density of the fluid, DT is the log of transient time, DTMA is the transient time of the matrix and DTF is the transient time of the fluid (Hook et al., 2003). Figure 3 shows $\phi D T$ (green curve) and $\phi R H O B$ (blue curve) plotted together with the laboratory porosity ( $\phi\llcorner A B$, black dots), with $\phi D T$ having a better fit with pLAB (track 7).

The Hingle cross plot RT-DT was used again to evaluate, this time, the resistivity of the formation water $(R w)$ together with the Archie equation $S_{w}=\left((a R w) /\left(R T \phi^{m}\right)\right)^{1 / n}$ (Archie et al., 1942). In the equation, a=tortuosity factor, $\mathrm{m}=$ cementation exponent, $\mathrm{n}=$ saturation coefficient, $\mathrm{p}=$ total porosity and $\mathrm{Sw}=$ water saturation. Thus, considering $a=0.81, m=2$ and $n=2, R w$ was evaluated by calculating the slope of the line with $\mathrm{Sw}=100 \%$ (light blue line in Figure 4). The resulting value of $0.019 \mathrm{ohm}-\mathrm{m}$ is very close to that found by Nacur (2014), which calculated $\mathrm{Rw}=0.02$ ohm.m (Figure 4). The Picket cross plot was used to estimate $S w$ with the lines of 1.0, 0.5, 0.2 and 0.1 utilizing the estimated Rw with the Hingle chart and the equation $\log (\phi \mathrm{DT})=((-1 / \mathrm{m}) \quad \mathrm{RT})$ $n \log (\mathrm{Sw})+\log (\mathrm{aRw})$. The region with lower $\mathrm{Sw}=0.1 \%$ was highlighted in light blue in the tracks, and, as it was expected, the regions of lower saturation are of areas of interest 1 and 2 mentioned before (Figure 5). Still in this figure, they were placed in the form of a track for $S w$ for the entire well (track 8). The Buckles cross plot Sw- $\phi\llcorner A B$ was constructed, and it was seen that the first area of interest has a Bulk Volume Water (BVW) between 0.01 and $0.02 \%$ (Greengold et al., 1986), indicating that the area produces little water (Figure 6).

The RHOB-NPHI cross plot is an important tool to identify the lithology, mainly the reservoir (Figure 7), which is presented in black dots and, the cementation having a high concentration of calcite and little dolomite (Carvalho et al.,1995). The region of clean sandstone (green), with calcite (pink) and dolomite (light blue) cementations is displayed in Figure 8 . The parameters $\mathrm{M}$ and $\mathrm{N}$ were calculated with the equations $\mathrm{M}=\left(\left(\mathrm{DT} \mathrm{T}_{\mathrm{F}}-\mathrm{DT}\right) /(\rho \mathrm{B}-\rho \mathrm{F})\right) 0.01$ and $\left.\left.N=\phi_{N F}-\phi_{N}\right) /\left(\rho_{B}-\rho_{F}\right)\right)$, where DT is the transient time $\log , D_{F}=D T$ in the fluid, $\rho_{B}$ is the density log, $\rho_{F}=\rho_{B}$ in the fluid, $\phi N$ is the neutron porosity log and $\phi N F=\phi N$ in the fluid. Then, the cross-plot MN was constructed having GR as the third axis (Figure 9). The reservoir is exhibited in blue points and its high porosity ( $27 \%$ ) is attributed to the dissolution of carbonate cement, in accord to Carvalho et al. (1995). The clay volume using V VHALE=(GRLOG -

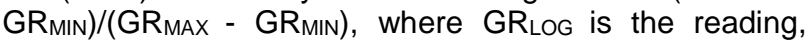
GRMAX is the maximum and GRMIN is the minimum values of the log and, highlighted in pink (Figures 8 and 9).

\section{Oilfield B}

By analyzing the basic logs of Well B17 in Oilfield B, it is possible to identify the region of interest ranging from the depth of 206 to $247 \mathrm{~m}$ (black rectangle, Figure 10). This reservoir has a low value in the GR log reading with values up to $15^{\circ} \mathrm{API}$ (track 2), which is common in carbonates. DT log increases from 80 to $110 \mathrm{~s} / \mathrm{ft}$, possibly associated with a rock compaction, in turn caused by a bigger cementation (track 3). The response of the RT log increases from 8 to $2000 \mathrm{ohm}$.m, indicating the presence of hydrocarbons (track 4). The porosity reduces in the means that RHOB log increases from 2.10 to 2.15 and the NPHI log decreases from 26 to $16 \%$. This is represented in the yellow shading of track 5 , which indicates the presence of hydrocarbons.

The Hingle cross plot was constructed to estimate pMA and DTMA in the rock matrix with the RHOB and DT logs. As can be seen in Figure 11, $\rho M A=2.726 \mathrm{gr} / \mathrm{cm}^{3}$ and $\mathrm{DT}_{\mathrm{MA}}=47.32 \mu \mathrm{s} / \mathrm{ft}$. In accord to Asquith \& Krygowski (2004) and Asquith \& Gibson (1982), the limestone goes from 47.6 to $49 \mu \mathrm{s} / \mathrm{ft}$ and, and, $\rho$ MA is on average 2.710 $\mathrm{gr} / \mathrm{cm}^{3}$ is on average $2.710 \mathrm{gr} / \mathrm{cm}^{3}$. For dolomite, DTMA goes from 43.5 to $44 \mu \mathrm{s} / \mathrm{ft}$, and, $\rho M A=2.877 \mathrm{gr} / \mathrm{cm}^{3}$. Hereafter, $\phi D T$ and $\phi R H O B$ were plotted along with $\phi\llcorner A B$ 
(track 6, Figure 12) and, $\mathrm{R}^{2}$ was estimated, having 0.22 and 0.11 , respectively. Then, $\phi \mathrm{DT}$ was used to calculate $\mathrm{Rw}=0.028$ ohm.m in the Pickett chart (Figure 13), using Archie equation and considering $a=1, m=2$ and $n=2$ (Archie et al., 1942). Vincentelli \& Contreras (2016) estimated Rw from 0.0270 to 0.0377 ohm.m in Albian carbonate reservoirs of the Quissama Formation.

Then, considering $\mathrm{Rw}=0.028$ ohm.m, the Pickett chart was used to estimate $\mathrm{Sw}$, drawing on it the lines of 1.0, $0.5,0.2$ and 0.1 (Figure 13). The region with $S w=0.1$ is the area of interest because it can have little water and too much oil. Still in this figure, the calculated Sw is very close to the value estimated by Petrobras (2012). Quantitatively, this good performance is confirmed, by keeping a $R^{2}=0.72$ and, the areas highlighting in light blue in Figure 14 (track 7). Using the average $\phi\llcorner A B$, it can be seen in Figure 15 that area of interest has BVW between 0.01 and $0.08 \%$.

The RHOB - NPHI cross plot shows the limestone as the predominant rock in the studied range of the well (Figure 16). Robaina et al. (1991) presented that calcite is the predominantly mineral, and secondarily, dolomite. Still according these authors, dolomitization is not very expressive, occurring especially in low energy facies. Figure 17 displays the high and medium energy areas highlighted in light blue and low energy areas displayed in pink. What was observed above can be confirmed in the MN graph, with the GR as third variable (Figure 18), used to separate the data by energy: high energy ( 0 to $20^{\circ} \mathrm{API}$,

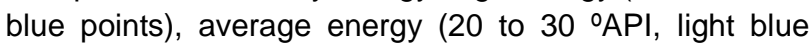
points) and low energy (30 to $120^{\circ} \mathrm{API}$, pink points). Also, this figure shows that the high and middle energy regions are dominated by limestone and, is the area of interest. In the low energy part prevails the dolomite, which goes up to $138 \mathrm{~m}$. Then, it can be verified that the reservoir is composed basically by limestone in the high and medium energy facies.

\section{Conclusions}

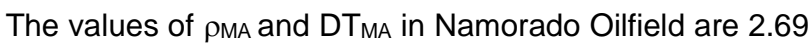
$\mathrm{gr} / \mathrm{cm}^{3}$ and $53.80 \mu \mathrm{s} / \mathrm{ft}$, respectively, using the Hingle plot. These results are close to $2.67 \mathrm{gr} / \mathrm{cm}^{3}$ and $53.52 \mu \mathrm{s} / \mathrm{ft}$, found by Ribeiro \& Stevanato (2011). Still using Hingle plot, it was found $R w=0.019$ ohm.m, result that goes according to what found by Nacur (2014). In the Picket plot, Sw values were found and the region of lower saturation (0.1) was highlighted in the tracks, which as expected were the regions of interest. And with the Buckles plot, it was possible to find a BVW of 0.01 to 0.02 for the first zone of interest, indicating that the region produces little water. The RHOB-NPHI graph showed that the clean sandstone is the main reservoir, which has a cementation with calcite higher than dolomite (Carvalho et al., 1995). In the MN plot it was possible to see that this reservoir has secondary porosity, in which Carvalho et al. (1995) attributes the dissolution of carbonate cement and it was also possible to verify the presence of clay, confirmed by the calculation of its volume and shown as a track. In Oilfield $B$ using Hingle the values $\mathrm{DT}_{\mathrm{MA}}=2.67$ $\mathrm{gr} / \mathrm{cm}^{3}$ and DTMA $=47.32 \mu \mathrm{s} / \mathrm{ft}$, which is in accordance with the values seen in the Asquith \& Krygowski (2004). Also, the value of $\mathrm{Rw}=0.028 \mathrm{ohm} . \mathrm{m}$ was found to be consistent with that found by Vincentelli \& Contreras (2016), which estimated Rw values in Albian carbonate reservoirs of the Quissamã Formation. The Pickett chart estimated $\mathrm{Sw}$ in the reservoir and the comparison with Petrobras value resulted in $R^{2}=0.72$. Still with Buckles it was possible to see that zone of interest of this reservoir has BVW between 0.01 to 0.08 . The RHOB-NPHI plot, the MN chart and Robaina et al. (1991) indicated limestone and calcite as the predominant rock and mineral, respectively, with a few dolomites at low energy facies. Using the GR log along these graphs, it was possible to see in the clues that the facies of high ( 0 to 20 $\circ \mathrm{API}$ ) and average (20 to $\left.30{ }^{\circ} \mathrm{API}\right)$ energy are dominated by calories and the low energy region ( 30 to $120 \cong \mathrm{API}$ ) are dominated by dolomites.

\section{Acknowledgments}

We thank Brazilian National Agency of Petroleum, Natural Gas and Biofuels (ANP) by the release of the data set, CNPq by the research grant, LR Senergy for software academic license and UENF - LENEP for their physical and computational infrastructure.

\section{References}

- Aguilera, R. 2004. Integration of geology, petrophysics, and reservoir engineering for characterization of carbonate reservoirs through Pickett plots. AAPG bulletin, v. 88, n. 4, p. 433-446.

- Archie, G. 1942. The electrical resistivity log as an aid in determining some reservoir characteristics. Transactions of the AIME, SPE, v. 146, n. 01, p. 54-62.

- Asquith, G., \& Krygowski, D. 2004. Basic relationships of well log interpretation. In: Asquith, G. \& Krygowski, D. 2004. Basic Well Log Analysis. AAPG Methods in Exploration Series, No. 16, p. 1-20.

- Asquith, G., \& Gibson, C. 1982. Basic well log analysis for geologists. AAPG Methods in Exploration Series, $216 \mathrm{p}$.

- Buckles, R. 1965, Correlating and averaging connate water saturation data. Journal of Canadian Petroleum Technology, Petroleum Society of Canada, v. 4, n. 01, p. 42-52.

- Burke, J.; Campbell Jr., R. \& Schmidt, A. 1969. The litho-porosity cross plot a method of determining rock characteristics for computation of log data. Presented at the SPE Illinois Basin Regional Meeting, Evansville, Indiana, 30-31 October. SPE-2771-MS. 
- Buryakovsky, L.; Chilingar, G.; Shin, S. \& Rieke, H. 2012. Fundamentals of the petrophysics of oil and gas reservoirs. John Wiley \& Sons, Inc., Hoboken, Nova Jersey, USA, $400 \mathrm{p}$.

- Carvalho, M.; Ros, L. \& Gomes, N. 1995. Carbonate cementation patterns and diagenetic reservoir facies in the Campos Basin Cretaceous turbidites, offshore eastern Brazil. Marine and Petroleum Geology, v. 12, n. 7, p. 741 .

- Chang, H.; Kowsmann, R.; Figueiredo, A. \& Bender, A. 1992. Tectonics and stratigraphy of the east Brazil rift system: an overview. Tectonophysics, Elsevier Science Publishers B.V., Amsterdam, v. 213, n. 1-2, p. 97-138.

- Clavier, C. \& Rust, D. 1976. MID plot: A new lithology technique. The Log Analyst, v. 17, no. 6, p. 16-24. Reprinted in 1986, in. Openhole well logging: SPE Reprint Series No. 21, p. 515-523.

- Formoso, M.; Robalna, I. \& Spadlnl, A. 1991. Carbonates reservoir of the Macae Formation, Campos Basin, RJ, Brazil. Part I - Contribution to the geochemistry of carbonates. Geochimica Brasiliensis, v. 5, n. 1 (In Portuguese).

- Greengold, G. 1986. The graphical representation of bulk volume water on the Pickett cross-plot. The Log Analyst, v. 27, n. 03.

- Guardado, L.; Gamboa, L. \& Lucchesi, C. 1989. Petroleum Geology of the Campos Basin: A model for producing Atlantic type basin. In: Edwards, J.D. and Santogrossi, P.A., eds., Divergent/Passive Margin Basins. AAPG Memoir, 48, p.3-79.

- Guardado, L.; Spadini, A.; Sartori, J. \& Mello, M. 2000. Petroleum systems of the Campos Basin, Brazil. In: Mello, M.R. and Kaltz, B.J., eds., Petroleum Systems of South Atlantic Margins. AAPG Memoir 73, p.317-324.

- Hingle, A. 1959. The use of logs in exploration problems. SEG 29th International Annual Meeting, Los Angeles, November.

- Hook, J. 2003. An introduction to porosity. Petrophysics, vol. 44, no. 3, p. 205-212.

- Kirby, J.; Culver, R. \& Mattei, J. 1960. Profitable application of well logs: Journal of Petroleum Technology, v. 12, no. 1, p. 17-22.

- LR Senergy. 2018. Interactive Petrophysics User's Manual.

- Macini, P. \& Mesini, E. 2002. Petrophysics and reservoir characteristics in petroleum engineering upstream. Encyclopedia of Life Support Systems (EOLSS), p. 1 10.

- Milani, E.; Brandão, J.; Zalan, P. \& Gamboa, I. 2000. Petroleum in the Brazilian continental margin: geology, exploration, results and perspectives. Brazilian Journal of Geophysics, Scielo Brasil, v. 18, n. 3, p. 351-396. (in Portuguese).

- Nacur, G. 2014. Analysis of water saturation of Namorado sandstone using well log data. Graduation
Monograph, Darcy Ribeiro Northern Rio de Janeiro State University, Macae - RJ, 84 p. (In Portuguese).

- Petrobras. 2012. Technical report of Field B. UENF / Fundenor / Petrobras Agreement. (In Portuguese).

- Pickett, G. 1973. Pattern recognition as a means of formation evaluation. The Log Analyst, v. 14, n. 04.

- Poupon, A.; Hoyle, W. \& Schmidt, A. 1971. Log analysis in formations with complex lithologies. Journal of Petroleum. Technology, v. 23, p. $995-1005$.

- Ribeiro, A. \& Stevanato, S. 2011. Petrophysical analysis of reservoir. Graduation Monograph, Campinas State University, Campinas, 74 p. (In Portuguese).

- Robaina, L.; Formoso, M. \& Spadini, A. 1991. Carbonates reservoir of the Macaé Formation, Campos Basin, RJ, Brazil. Geochimica Brasiliensis, v. 5, p. 6978. (In Portuguese).

- Schön, J. 2015. Physical properties of rocks: Fundamentals and principles of petrophysics. Elsevier, Amsterdam, The Netherlands, $512 \mathrm{p}$.

- Tiab, D. \& Donaldson, E. 2015. Petrophysics: Theory and practice of measuring reservoir rock and fluid transport properties. Gulf Professional Publishing, Elsevier, Amsterdam, The Netherlands, $918 \mathrm{p}$.

- Tittman, J. 1986. Geophysical well logging. Elsevier Academic Press, Amsterdam, The Netherlands, $186 \mathrm{p}$.

- Vincentelli, M. \& Contreras, S. 2016. Water saturation on Albian carbonates reservoirs - ancient Brazilian oil fields. Journal of Geophysics and Engineering, IOP Publishing, v. 13, n. 6, p. 880.

Table 1. Properties derived from the application of cross-plots: $\rho M A$ (matrix density) DTMA (matrix delay time), Rw (formation water resistivity), BVW (bulk volume water) and Sw (water saturation)

\begin{tabular}{|c|c|}
\hline Cross Plot & Property \\
\hline Hingle (1959) & $\rho \mathrm{MA}, \mathrm{DT}_{\mathrm{MA}}$ and $\mathrm{Rw}$ \\
\hline Buckles (1965) & BVW \\
\hline Pickett (1973) & Sw \\
\hline Neutron - density logs & Lithology \\
\hline M-N & Lithology \\
\hline
\end{tabular}




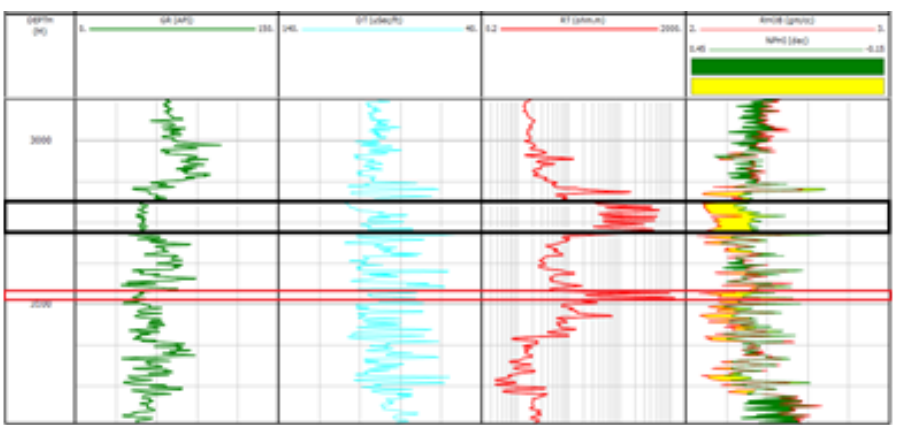

Figure 1. Areas of interest in Well NA02 of Namorado Oilfield. Tracks: 1- Depth (m), 2- GR log, 3- DT log, 4- RT log and 5- RHOB and NPHI logs.

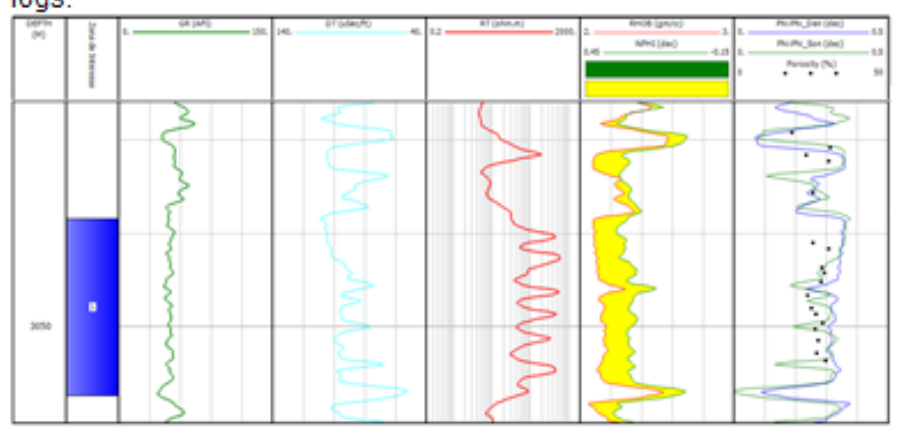

Figure 3. Plots of $\phi_{\mathrm{RHOB}}$ and $\phi_{\mathrm{NPHI}}$ compared with $\phi_{\mathrm{LAB}}$ in the first zone of interest in Well NA02 of Namorado Oilfield (track 7). Tracks: 1Depth (m), 2- interest zone, 3- GR log, 4- DT log, 5- RT log, 6- RHOB and NPHI logs and $7-\phi_{\mathrm{RHOB}}, \phi_{\mathrm{NPHI}}$ and $\phi_{\mathrm{LAB}}$.

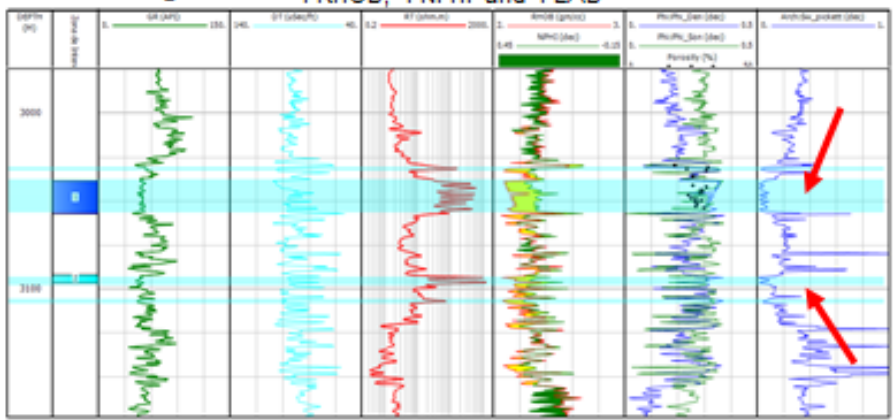

Figure 5. Regions highlighted in light blue with $\mathrm{Sw}=0.1$ in Well NA02 of Namorado Oilfield (track 2). Tracks: 1- Depth (m), 2- interest zones, 3GR log, 4- DT log, 5- RT log, 6- RHOB and NPHI logs, 7- $\phi_{\text {RHOB, }}$ $\phi_{\mathrm{NPHI}}$ and $\phi_{\mathrm{LAB}}$ and 8- Sw (\%).

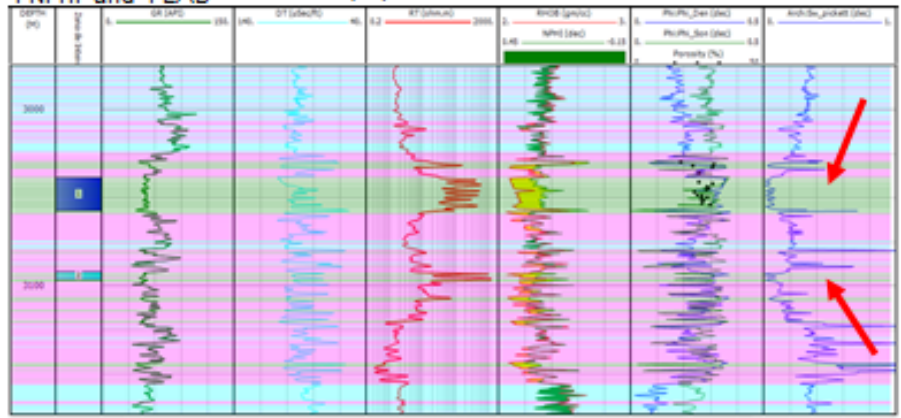

Figure 8. Regions of clean sandstone (green), with calcite cementatior (pink) and dolomite cementation (blue) in Well NA02 of Namorado Oilfield. Tracks: 1- Depth (m), 2- interest zones, 3- GR log, 4- DT log, 5- RT log, 6RHOB and NPHI logs, 7- $\phi_{\mathrm{RHOB}}, \phi_{\mathrm{NPHI}}$ and $\phi_{\mathrm{LAB}}$ and 8- Sw (\%).
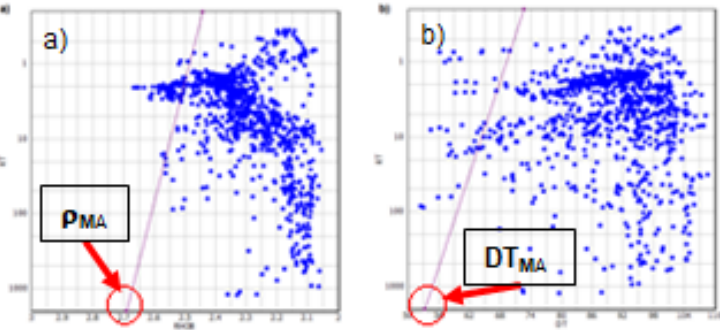

Figure 2. Hingle cross plot with: a) RT (ohm.m) vs RHOB $\left(\mathrm{gr} / \mathrm{cm}^{3}\right)$ and b) RT (ohm.m) vs DT (us/ft) in Well NA02 of Namorado Oilfield.

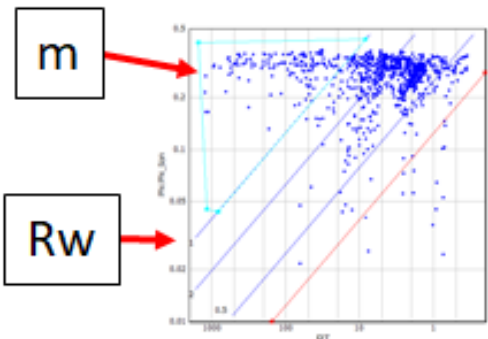

Figure 4. Pickett cross plot $\phi_{D T}^{\mathrm{RT}}(\%)$ vs RT (ohm.m) with Sw (\%) lines: $1.0,0.5,0.2$ and 0.1 in Well NA02 of Namorado Oilfield.

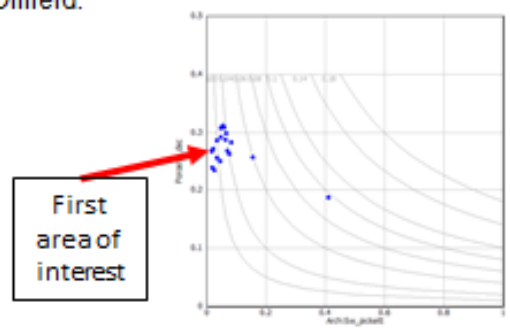

Figure 6. Buckes cross plot $\phi_{L A B}(\%)$ vs $S w(\%)$ to determine BVW (different curves) in Well NA02 of Namorado $\mathrm{O}^{*}$

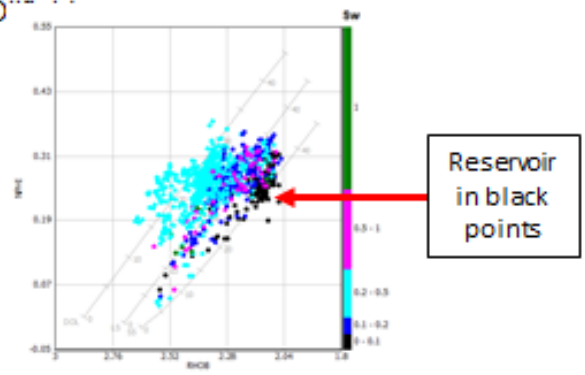

Figure 7. Lithology cross plot of RHOB vs NPHI logs with Sw calculated by Pickett chart in the color scale in Well NA02 of Namorado Oilfield.

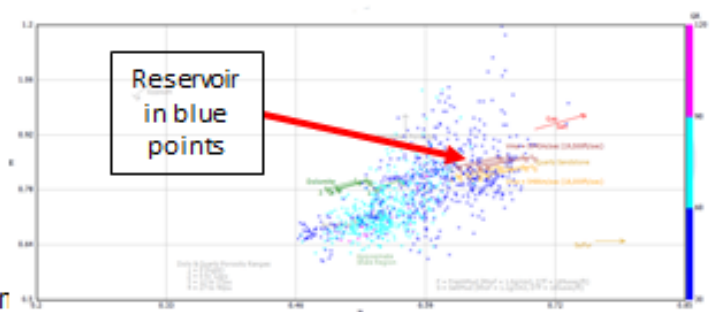

Figure 9. $\mathrm{M}$ - $\mathrm{N}$ cross plot with GR log as third variable in Well NA02 of Namorado Oilfield. 


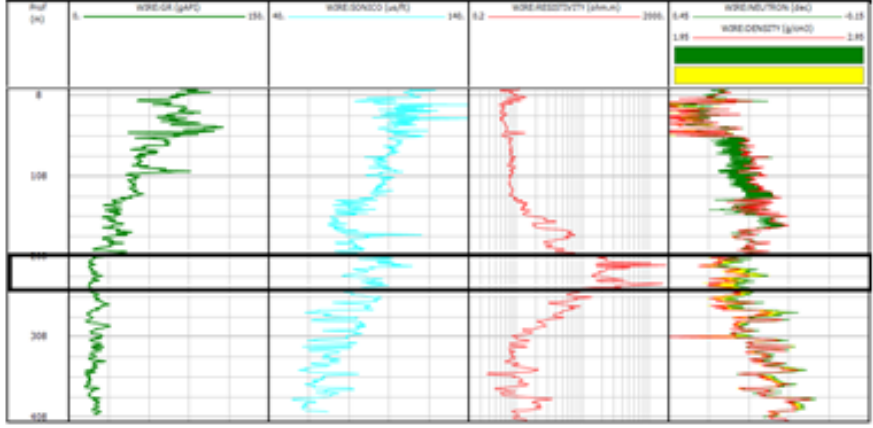

Figure 10. Area of interest in Well B17 Oilfield B. Tracks: 1- Depth $(\mathrm{m})$, 2-GR $\log , 3-\mathrm{DT} \log , 4-\mathrm{RT} \log$ and 5- RHOB and NPHI logs.

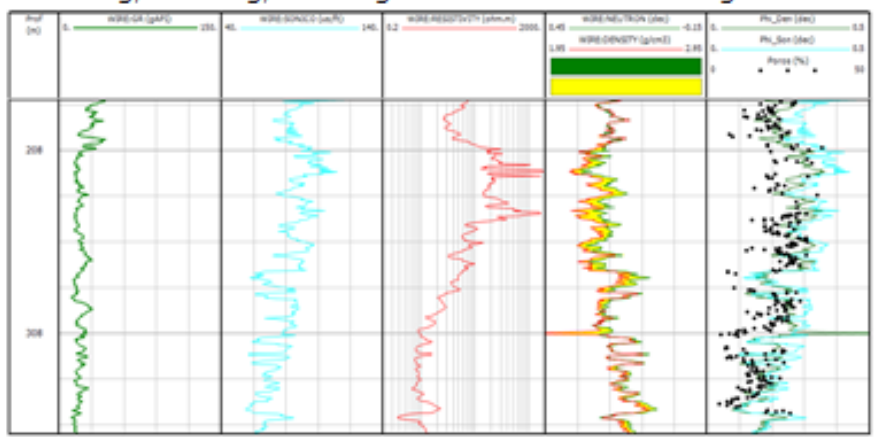

Figure 12. Plots of $\phi_{\mathrm{RHOB}}$ and $\phi_{\mathrm{NPHI}}$ compared with $\phi_{\mathrm{LAB}}$ in area of interest in Well B17 Oilfield B (track 6). Tracks: 1- Depth (m), 2- GR log, 3- DT log, 4- RT $\log$ and 5- RHOB and NPHI logs.

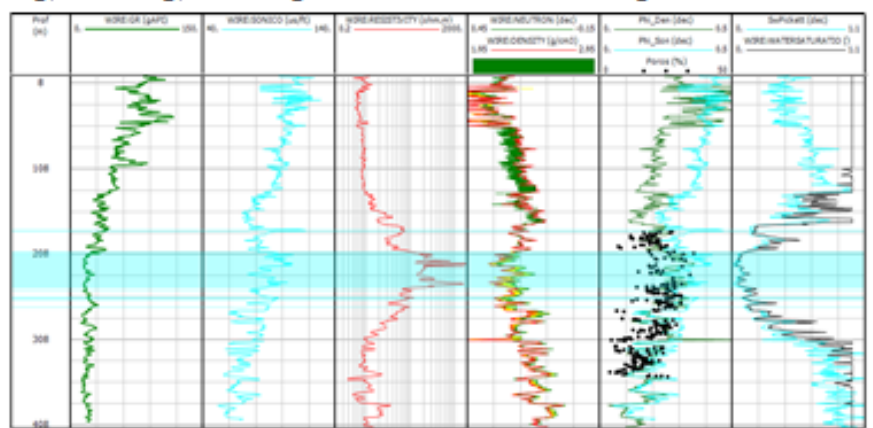

Figure 14. Region highlighted in light blue with $S w=0.1$ in Well B17 Oilfield B (track 1). Tracks: 1- Depth (m), 2- GR log, 3- DT log, 4- RT log, 5- RHOB and NPHI logs, 6- $\phi_{\mathrm{RHOB}}, \phi_{\mathrm{NPHI}}$ and $\phi_{\mathrm{LAB}}$ and 7- SW (\%).

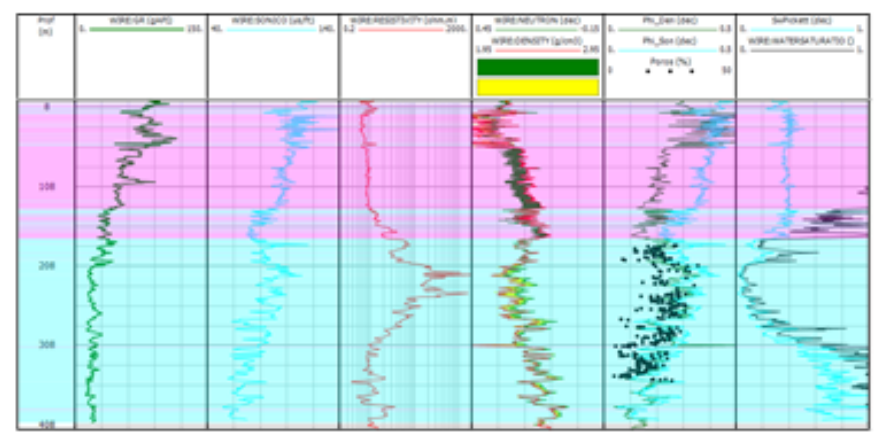

Figure 17. High and medium energy zones are highlighted in light blue and low energy zones in pink. in Well B17 Oilfield B. Tracks: 1- Depth $(\mathrm{m}), 2$ GR log, 3- DT log, 4- RT log, 5- RHOB and NPHI logs, 6- $\phi_{\mathrm{RHOB}}, \phi_{\mathrm{NPHI}}$ and $\phi_{L A B}$ and 8- Pickett and Archie Sw (\%).
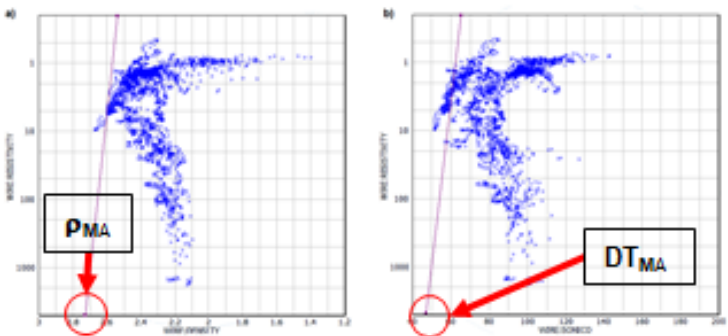

Figure 11. Hingle cross plot with: a) RT (ohm.m) vs RHOB $\left(\mathrm{gr} / \mathrm{cm}^{3}\right)$ and b) RT (ohm.m) vs DT ( $\left.\mu \mathrm{s} / \mathrm{ft}\right)$ in Well B17 Oilfield B.

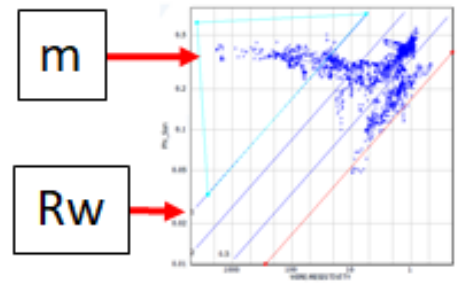

Figure 13. Pickett cross plot $\phi_{\mathrm{DT}}(\%)$ vs RT (ohm.m) with Sw (\%) lines: 1.0, 0.5, 0.2 and 0.1 in Well B17 Oilfield B.

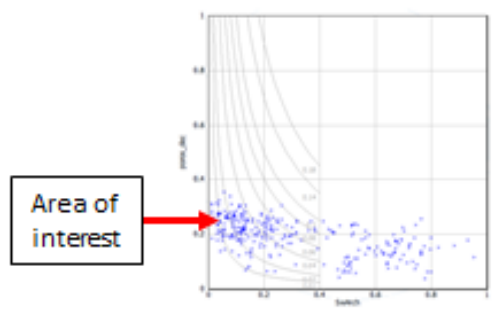

Figure 15. Buckles cross plot $\phi_{L A B}(\%)$ vs $S w(\%)$ to determine BVW (different curves) in Well B17 Oilfield B.

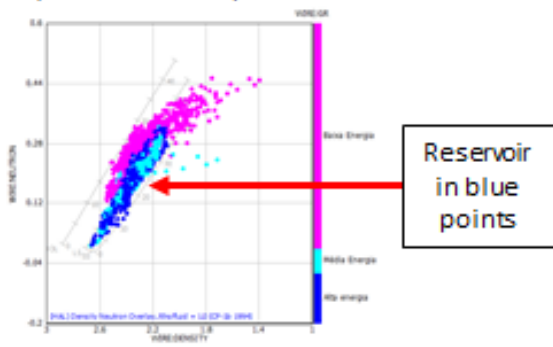

Figure 16. Lithology cross plot of RHOB vs NPHI logs with Sw calculated by Pickett chart in the color scale in Well B17 Oilfield B.

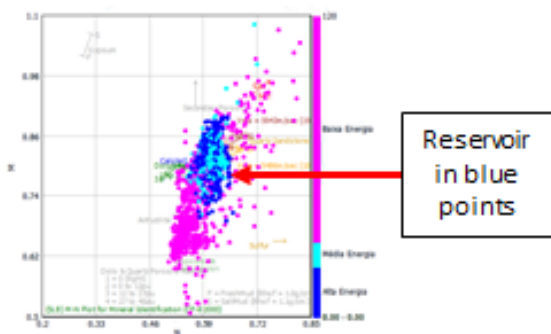

Figure 18. $\mathrm{M}-\mathrm{N}$ cross plot with GR log as third variable in Well B17 Oilfield B. 